\title{
Forest Fire Research: The Latest Advances Tools for Understanding and Managing Wildland Fire
}

\author{
Paul-Antoine Santoni, ${ }^{1}$ Andrew Sullivan, ${ }^{2}$ Dominique Morvan, ${ }^{3}$ and William E. Mell ${ }^{4}$ \\ ${ }^{1}$ University of Corsica Pascal Paoli, Campus Grimaldi, SPE UMR 6134 CNRS, BP 52, 20250 Corte, France \\ ${ }^{2}$ CSIRO Ecosystem Sciences and CSIRO Climate Adaptation Flagship, GPO Box 1700 Canberra, ACT 2601, Australia \\ ${ }^{3}$ Aix-Marseille Université, UNIMECA, 60 Rue Joliot Curie, 13453 Marseille cedex 13, France \\ ${ }^{4}$ U.S. Forest Service, Pacific Wildland Fire Sciences Lab, 400 N. 34th St., Suite 201, Seattle, WA 98103, USA \\ Correspondence should be addressed to Paul-Antoine Santoni, santoni@univ-corse.fr
}

Received 4 December 2011; Accepted 4 December 2011

Copyright (c) 2011 Paul-Antoine Santoni et al. This is an open access article distributed under the Creative Commons Attribution License, which permits unrestricted use, distribution, and reproduction in any medium, provided the original work is properly cited.

Wildfire is one of the most complex and dangerous natural phenomena studied in the world. Combining the complicated chemistry and physics of solid and gas phase combustion and transfer of heat with spatially variable vegetation and topography and spatially and temporally varying weather conditions across a range of spatial and temporal scales, wildfires present a considerable challenge to predict and control. In the last fifteen years, the scientific community has considerably increased its efforts to betterunderstand wildfires through improvements in observation, measurement, analysis, and modeling. This has been facilitated by rapid development in the fields of spatial data analysis and computing ability. This combination has enabled the development of new decision support systems and information gathering and analysis methods, as well as the improvement of existing tools for managing fires. Despite this activity, forest fires remain a serious issue in many countries. Climate change, rural-urban migration, and the growth of the urban-wildland interface are some of the factors leading to an increase in wildfire hazard around the world. The extreme fires that occurred in Australia in 2009 (Black Saturday, 7 February 2009) burned more than 400000 hectares and killed 173 people. Such events clearly show the formidable destructive force of high-intensity wildfires, often well beyond our current ability to suppress and control. The scientific community is, along with firefighters, foresters, and other organized structures, one of the keys to successfully face the challenges of understanding fire in the landscape. Advances in our knowledge of the driving mechanisms of wildland fire and the interaction of fire behavior with the natural and built environments will lead to more efficient decision support systems for fire danger rating, fire spread prediction, and fire hazard mitigation.

For this special issue on forest fire, we considered 15 original submitted manuscripts; 9 papers were accepted for publication in this Journal. The topics covered by these contributions include a decision support tool to support risk-informed decision-making for individual fires (E. K. Noonan-Wright et al.), geospatial analysis for wildland fire risk assessment and fuel management planning (A. A. Ager et al.), surface fire modeling at landscape scale (P.-A. Santoni et al.), and simulation of coupled fire/atmosphere interaction (J.-B. Filippi et al.). A simple technique to estimate the flammability index of forest fuel was proposed (M. Hachmi et al.) for the fire risk mapping. Other topics covered in this issue concern extreme fire behavior and safety issue in the case of fire-fire interaction and mass fire (M. A. Finney and S. S. McAllister) and for vortices interaction with fires, like horizontal roll vortices (J. M. Forthofer and S. L. Goodrick). An observational study details the formation of a fire whirl during a low intensity prescribed fire (D. Seto and C. B. Clements). Finally, an investigation of radiation emitted by optically thin and thick flames (P. Boulet et al.) emphasizes the importance of fundamental studies to improve our knowledge of heat transfer in fires.

We would like to express our thanks to the reviewers that gave up their time to read and discuss the submitted papers. This special issue would not have been possible without their 
contribution. Their instructive comments and suggestions have helped to improve all papers. We wish that the papers published in this special issue on forest fires will inspire future research and cooperation.

Paul-Antoine Santoni Andrew Sullivan

Dominique Morvan William E. Mell 

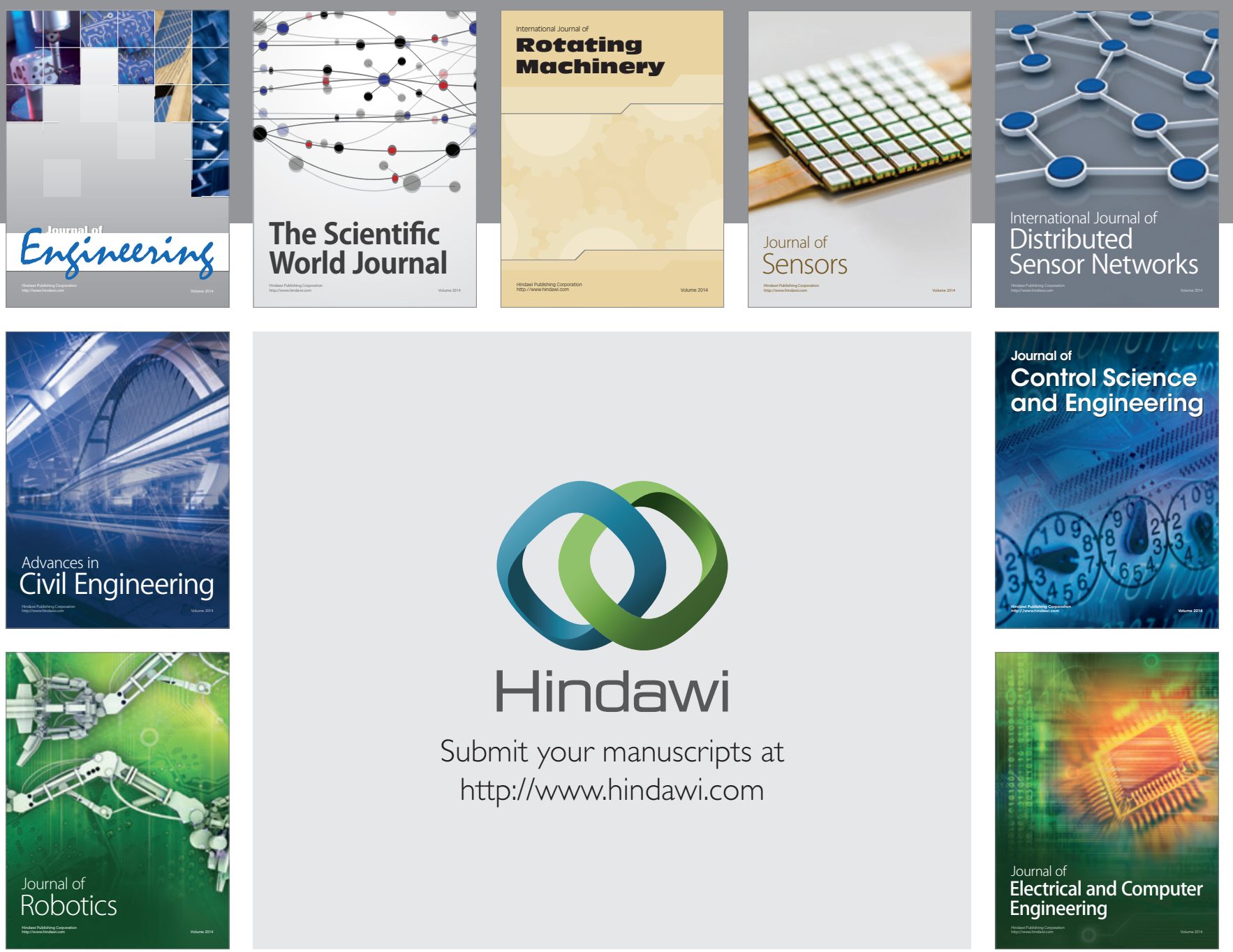

Submit your manuscripts at

http://www.hindawi.com
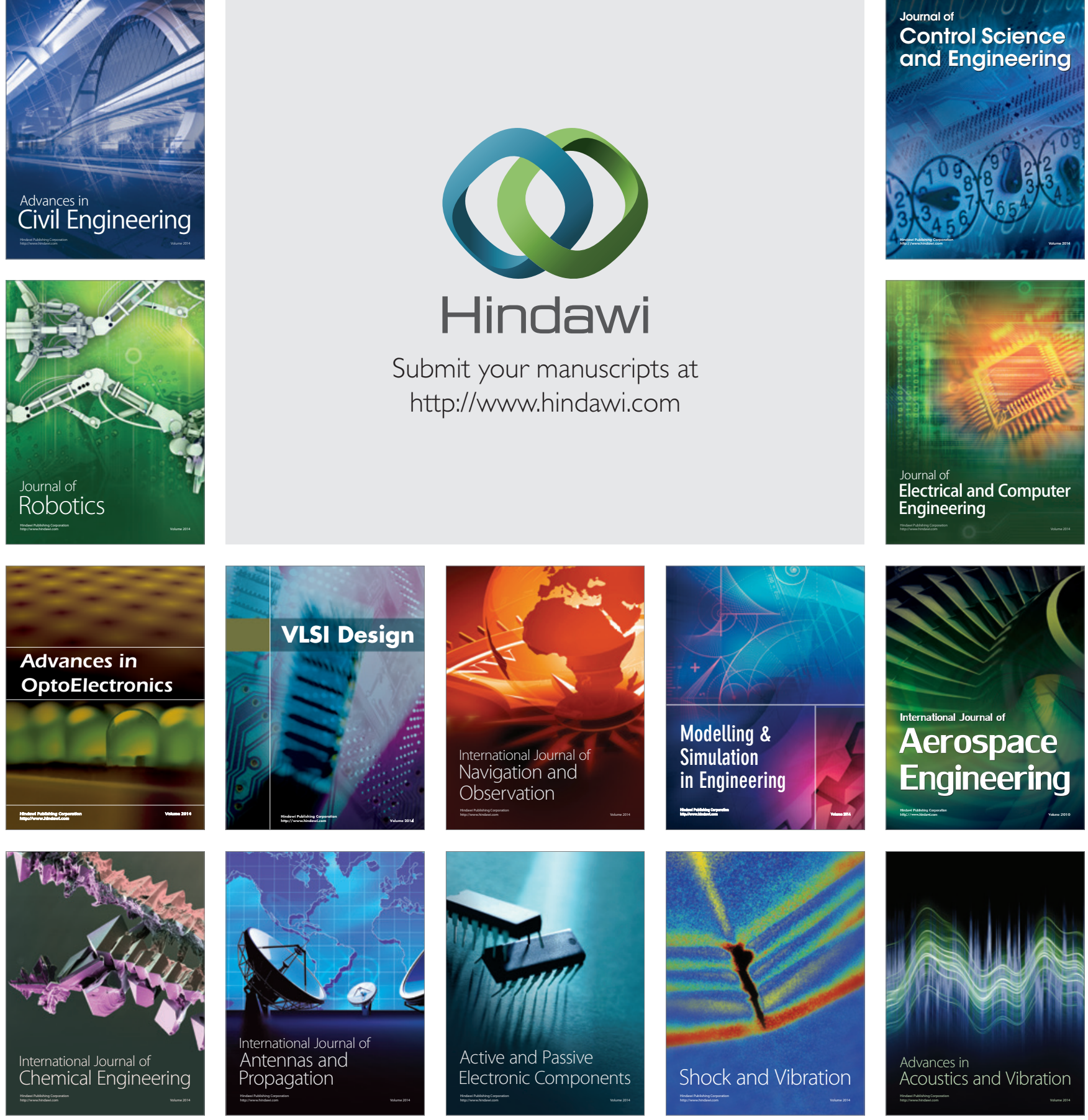